\title{
Idiosyncratic and Aggregate Risks, Inequality and Growth
}

\author{
Yoseph Getachew ${ }^{*}$ a \\ ${ }^{a}$ Department of Economics, University of Pretoria, Pretoria, South Africa
}

\begin{abstract}
The paper disaggregates productivity shocks at a firm level into idiosyncratic and aggregate risks, and studies their impacts on inequality, growth and welfare. It develops a growth model with human capital and incomplete insurance and credit markets that provides a closed-form solution for income inequality dynamics. We find that uninsured idiosyncratic risks are the most important determinants of inequality, growth and welfare. They are the source of nondegenerate wealth distribution. A lower weight of these shocks leads to lower steady-state inequality, higher growth and welfare. A redistribution of income that serves as social insurance against such risks increases welfare and decreases inequality. But, it also decreases growth by distorting individual consumption and saving decisions.
\end{abstract}

Key words:

Aggregate and idiosyncratic shocks, inequality, growth, incomplete market JEL Classification: D3, E1, O4

\footnotetext{
${ }^{*}$ Corresponding author: Tel.: +27124204509

Email address: yoseph.getachew@up.ac.za (Yoseph Getachew)
} 


\section{Introduction}

Idiosyncratic and aggregate risks play an increasingly important role in macroeconomics. In business cycle literature, two questions dominate the debates surrounding them. The first concerns the welfare effects of business cycles. In an influential article, Lucas (1987) argues that the welfare gain from eliminating business cycles is very small. Subsequent important work has challenged Lucas's findings. Particularly, Atkeson and Phelan (1994), Storesletten et al. (2001), Krebs (2003), Turnovsky and Bianconi (2005), and Krusell et al. (2009) criticize his method of focusing on aggregate shock and document a substantial welfare cost of business cycles after taking into consideration idiosyncratic shocks.

The second issue concerns the source of business cycles. Initially, Lucas (1977) disregarded the microeconomic explanation for aggregate fluctuations (such as employment and output variations) invoking the law of large numbers. Subsequently, however, multiple mechanisms were identified that could defy the "averaging out" of individual shocks. ${ }^{1}$ Long and Plosser (1983) laid the foundation with their work focusing on idiosyncratic disturbances as the source of business cycles through a propagation effect that is generated across sectors. A number of empirical studies followed that showed that both idiosyncratic and aggregate shocks are important sources of sectoral and aggregate output variations (e.g. Long and Plosser, 1987, Horvath, 1998, Foerster et al., 2011). ${ }^{2}$

More recently, and closely related to this paper, there has been a growing interest in the relation of shocks to inequality and growth. For instance, Ramey and Ramey (1995), Blackburn and Galindev (2003), Imbs (2007), Badinger (2010), and Varvarigos (2013) find aggregate fluctuations important determinants of growth. GarciaPenalosa and Turnovsky (2005) study the effects of volatility on factor shares while Checchi and Garcia-Penalosa (2004) argue that economies with greater risks end up with lower output and higher inequality under a perfect credit market scenario. ${ }^{3}$ Becker and Tomes (1979), Krusell and Smith (1998) and Benabou (2000, 2002),

\footnotetext{
${ }^{1}$ Such as (i) covariability due to the presence of common factors (e.g. Long and Plosser, 1987, Foerster et al., 2011), (ii) complementarity and input-output linkages (e.g. Long and Plosser, 1983, Horvath, 1998), (iii) and the "granular" effects of large firms (Gabaix, 2011).

${ }^{2}$ According to Long and Plosser (1987), aggregate factors account for about $47 \%$ of the USA's aggregate output variation, whereas these are able to explain $40 \%$ of sectoral disturbances, at the most. Foerster et al. (2011) find that, between 1972 and 1983, aggregate shocks were important sources of sectoral disturbances, explaining about $41 \%$ of those that occurred (the median value). They were less important during the Great Moderation (1984-2007), however, as only around 19\% of cases of variability in sectoral output growth could be attributed to aggregate shocks.

${ }^{3}$ See Breen and Garcia-Penalosa (2005) for an empirical perspective.
} 
on the contrary, emphasize the role of idiosyncratic shocks on income and wealth distribution.

A common feature of this literature is that it often considers risks in isolation. ${ }^{4}$ Therefore their relative importance to growth and inequality is little known. The present paper endeavours to fill this gap. The paper in particular disaggregates productivity shocks at a firm level into idiosyncratic and aggregate risks, and studies their link and relative importance to growth, inequality and welfare. Using a variant of the Ramsey model, it develops a simple endogenous growth model with human capital in which productivity shocks at a firm level are decomposed into common and firm-specific components. In the model, agents are heterogeneous in terms of initial human capital and idiosyncratic productivity. Credit and insurance markets are missing, as in Loury (1981), Banerjee and Newman (1993), Galor and Zeira (1993), Benabou (2000, 2002), Getachew (2010, 2012), Basu and Getachew (2015) and Getachew and Turnovsky (2015). ${ }^{5}$ Individual production functions are characterized by inter-generational and intra-generational learning-by-doing externalities, which are the source of long-run growth - in the spirit of Romer (1986) and Lucas (1988).

Using a closed-form characterization of wealth distribution, we show that the variance of idiosyncratic shocks and their relative weight are among important determinants of the long-run distribution of wealth. Intuitively, inequality transmits across generations through past episodes of luck and initial wealth differences. With the presence of uninsurable idiosyncratic risks, inequality sustains in the long run due to individuals' inability to overcome initial differences in luck. Credit market imperfection, on the other hand, prevents the optimal amount of investment from being undertaken in the economy and makes the initial wealth differences persistent, as individuals with low initial human capital but a high marginal product of human capital cannot borrow from individuals with opposite traits. Inequality will then have a bad influence on growth and welfare. Idiosyncratic uninsurable risks will thus impact equilibrium growth and welfare indirectly via the effect on inequality. They also impact welfare directly. A smaller weight of the idiosyncratic shocks (vis-à-vis the aggregate shock) implies a lower steady-state inequality and a higher growth and

\footnotetext{
${ }^{4}$ The work by Turnovsky and Bianconi (2005) is an exception, although they give little emphasis to inequality. Our paper complements their work.

${ }^{5}$ However, this literature does not address risk composition and its relative macroeconomic implications. For instance, Basu and Getachew (2015) study the role of human capital adjustment costs (such as strong family ties) in intergenerational mobility. Loury (1981), Galor and Zier (1993) as well as Benabou (2000,2002) focus on human capital inequality and growth while Getachew and Turnovsky (2015) examine the relationship between public investment, inequality and growth.
} 
welfare. Aggregate risks, on the contrary, have no effect on steady-state inequality, as these risks are commonly shared among individuals. However, aggregate volatility have a negative influence on growth and welfare, though trivial quantitatively.

The quantitative analysis of the model suggests that idiosyncratic shocks are the most important determinants of welfare. We have found, using parametric values that reasonably reflect real economies, totally eliminating the idiosyncratic shocks could increase welfare by more than $16 \%$. However, in agreement with Lucas's (1987) finding, eliminating aggregate shocks barely affect welfare. Idiosyncratic risks are also important determinants of inequality and growth. If the weight of these shocks lowers by 0.20 points from its baseline value, for instance, steady-state inequality declines by more than $33 \%$. Fully eliminating the idiosyncratic shocks could also result in an additional $2.9 \%$ point rise in the equilibrium growth rate. This is in sharp contrast to a trivial gain in growth (less than a $0.10 \%$ point rise) that we get by eliminating the aggregate shocks. We also find that a redistribution of income, which could serve as social insurance against such risks, increases welfare and decreases inequality. But, it also decreases growth by distorting individual consumption and saving decisions.

The rest of the paper is organized as follows: Section 2 presents the model. Section 3 analyzes the dynamic and equilibrium properties of the model, and provides analytical solutions. In Section 4, we introduce government interventions in the form of income redistributions and progressive taxation. Section 5 studies the model quantitatively while Section 6 draws conclusions.

\section{The model}

Suppose that there is a continuum of infinitely-lived heterogeneous households, $i \in[0,1]$. Each of these households is initially endowed with $h_{i 0}$ units of capital, and each household runs its own private enterprise. Households are thus both consumers and entrepreneurs, as in the models of Angeletos and Calvet (2006). Similar to Loury (1981), the credit and insurance markets are missing.

\subsection{Preferences and technology}

The $i$ th household wishes to maximize the following logarithmic utility function:

$$
U_{i 0} \equiv \mathrm{E}_{0} \sum_{t=0}^{\infty} \rho^{t} \ln c_{i t}
$$

where $\mathrm{E}_{0}$ denotes the agent's expectation over the realization of productivity shocks at the initial date; $\rho<1$ is the discount factor. The household chooses consumption $c_{i t}$ to maximize its intertemporal utility. The unitary inter-temporal elasticity of 
substitution utility function is important for the model's analytical tractability. Such an assumption is ubiquitous in literature on economic growth and income distribution dynamics (see, for instance, Benabou, 2000, 2002).

In period $t$, the $i$ th individual utility function is subject to budget constraints:

$$
\begin{aligned}
y_{i t} & =c_{i t}+s_{i t} \\
y_{i t} & =a \vartheta_{i t}\left(h_{i t}\right)^{\alpha}\left(h_{t}\right)^{1-\alpha} \\
h_{i t+1} & =b\left(h_{i t}\right)^{1-\omega}\left(s_{i t}\right)^{\omega}
\end{aligned}
$$

where

$$
\vartheta_{i t} \equiv(1-\theta) \phi_{t}+\theta \epsilon_{i t}
$$

and

$$
a, b>0 ; \omega, \alpha, \theta \in(0,1)
$$

$c_{i t}, s_{i t}$, and $y_{i t}$ stand for the agent's consumption, saving, and income, respectively. $h_{i t}$ represents the $i$ th agent's human capital at time $t$ whereas $h_{t}$ denotes the average level of human capital or knowledge available in period $t .^{6}$

Eq. (2a) shows that the agent allocates income between current consumption and saving. The latter is used for investment in the human capital accumulation of the agent in the next period. According to (2b) and (2c), production technologies at the individual household level are characterized by both intergenerational and learningby-doing externalities - in the spirit of Romer (1986) and Lucas (1988). In eq. (2c), the production of the next-period human capital $\left(h_{i t+1}\right)$ takes place with the aid of the current human capital $\left(h_{i t}\right)$ and investment in schooling $\left(s_{i t}\right)$. We assume that the distribution of capital is log-normal:

$$
\ln h_{i t} \sim N\left(\mu_{t}, \sigma_{t}^{2}\right)
$$

In addition, for analytical convenience, human capital is assumed to fully depreciates within each period; and labour is inelastically supplied. ${ }^{7}$

Individual incomes are subject to productivity shocks, which determine their total marginal productivity. A key aspect of eq. (2b) is the decomposition of productivity

\footnotetext{
${ }^{6}$ One may consider (2b) as the income net of the cost of physical capital.

${ }^{7}$ There is no loss of generality with this assumption because the optimal choice of labour entails a constant fraction of income in a logarithmic utility function.
} 
shocks into idiosyncratic and aggregate risks. Intuitively, it is plausible that individual firms face economic uncertainty in the form of idiosyncratic risks, such as lower demands while they are subject to economy-wide shifts in recession and technology. We capture this in eq. (2b) where the total productivity shocks experienced by the $i$ th firm are composed of idiosyncratic shocks $\epsilon_{i t}$ and a common or an economy-wide shocks $\phi_{t}$. The relative weight of these shocks is captured by the relations in the parameter $\theta$. The shocks are assumed to be i.i.d., have a mean of one and follow the process: ${ }^{8}$

$$
\begin{aligned}
& \ln \epsilon_{i t} \sim \mathrm{N}\left(-v^{2} / 2, v^{2}\right) \\
& \ln \phi_{t} \sim \mathrm{N}\left(-\chi^{2} / 2, \chi^{2}\right)
\end{aligned}
$$

We adopt Turnovsky and Bianconi's (2005) approach that the two shocks enter individual production functions as substitutes, and that they are uncorrelated. In a later section, however, we allow interactions between the shocks.

\subsection{Optimal individual human capital accumulation}

The optimal solutions for the $i$ th household are given by (see Appendix A.2 for details)

$$
\begin{aligned}
c_{i t} & =(1-\varkappa) y_{i t} \\
s_{i t} & =\varkappa y_{i t}
\end{aligned}
$$

where

$$
\varkappa \equiv \rho \alpha \omega /(1-\rho(1-\omega))
$$

Eq. (6) captures the optimal consumption and saving of this household. Households thus consume a constant fraction of their income. ${ }^{9}$ Their optimal decisions are independent of the realization of the stochastic process, a direct consequence of their logarithmic preferences.

Then the optimal individual capital accumulation function is easily derived by substituting $(2 \mathrm{~b})$ and $(6 \mathrm{~b})$ into $(2 \mathrm{c})$ :

\footnotetext{
${ }^{8}$ Alternatively, one may consider an $\mathrm{AR}(1)$ process such as $\ln \left(\phi_{t}\right)=\delta \ln \left(\phi_{t-1}\right)+\varepsilon_{t}$ where $\varepsilon_{t} \sim N\left(0, \chi^{2}\right)$, which leads to similar results.

${ }^{9}$ Note that given the restriction in $(3), 0<\varkappa<1$.
} 


$$
h_{i t+1}=\psi\left(\vartheta_{i t}\right)^{\omega}\left(h_{i t}\right)^{\beta}\left(h_{t}\right)^{1-\beta}
$$

where

$$
\beta \equiv 1-\omega(1-\alpha)
$$

$\psi \equiv b(\varkappa a)^{\omega}$ and $\vartheta_{i t}$ are the non-stochastic and the stochastic total factor productivities of human capital accumulation, respectively. Eq. (7) captures the evolution of human capital at the individual household level that considers the household's optimal behaviour. Both individual and economy-wide human capitals and idiosyncratic and common shocks are important for the dynamics of individual human capital. $\beta$ and $1-\beta$ capture the intergenerational linkages that account for individual and aggregate factors in the economy, respectively. We see below $\beta$ is the main determinant of the evolution of inequality. It is independent of idiosyncratic and aggregate risks, but crucially dependent on the structure of the production and human capital accumulation technologies at the individual household level.

\section{Aggregate and disaggregate shocks, inequality, and growth}

\subsection{Transitional dynamics}

The aggregate human capital and the dynamics of inequality are derived from (7), which leads to the following proposition:

Proposition 1. The closed-form solutions for the distributional dynamics and the evolution of aggregate human capital are given by, respectively:

$$
\begin{aligned}
\sigma_{t+1}^{2} & =\beta^{2} \sigma_{t}^{2}+\omega^{2} \Omega_{t} \\
\gamma_{t+1} & \equiv \ln h_{t+1}-\ln h_{t}=\ln \psi+\omega \ln \varphi_{t}-\digamma_{t}
\end{aligned}
$$

where

$$
\begin{aligned}
\Omega_{t} & \equiv \ln \left(1+z \varphi_{t}^{-2}\right) \\
\varphi_{t} & \equiv(1-\theta) \phi_{t}+\theta \\
z & \equiv \theta^{2}\left(\exp \left(v^{2}\right)-1\right) \\
\digamma_{t} & \equiv 0.5\left(\sigma_{t}^{2} \beta(1-\beta)+\omega(1-\omega) \Omega_{t}\right)
\end{aligned}
$$

Proof. See Appendix A.1.

Eq. (8) explicitly defines the evolution of inequality and aggregate capital in the economy. Four observations immediately follow: Firstly, the root of the dynamic 
equation that characterizes the evolution of inequality only depends on the structure of production and human capital accumulation technologies such as the private factor share $(\alpha)$ and human capital investment elasticity $(\omega)$. Secondly, strong private intergenerational linkage (greater $\beta$ ) implies slow convergence in inequality. Thirdly, the dynamics of inequality is history dependent; however, this is not the case for the dynamics of aggregate capital. The evolution of aggregate human capital capital (8b) depends, rather, on the dynamics of inequality. Finally, the term $\digamma_{t}$ in $(8 \mathrm{~b})$, captures the short-run relationship between current inequality (represented by the variance of the $\log$ of human capital, $\sigma_{t}^{2}$ ) and next period growth. Because $\digamma_{t}$ increases in $\sigma_{t}^{2}$ and $\digamma_{t}>0$, the relationship is always negative.

\subsection{Long-run equilibrium}

Eq. (8) forms a system of the difference equations that characterize the dynamics of the economy. The dynamic system has a stable long-run equilibrium for plausible parameter specifications, $0<\beta<1$. Because inequality is the driving force of transitional dynamics in the economy, once it reaches its long-run equilibrium, the whole system will be in equilibrium.

There are at least two ways to derive the long-run (trend) equilibrium of a stochastic economy. The first way is letting the stochastic process $\phi_{t}$ takes mean value every single period, leading to a steady-state value $\phi=1 .^{10}$ The second way is to make an approximation around the deterministic steady state and then derive the trend equilibrium values (see, for e.g., Blackburn and Varvarigos, 2008). We use the second approach, as we wish to keep aggregate volatility and examine its macroeconomic effects quantitatively (in a later section).

We thus approximate the two nonlinear terms in eq. (8) $\left(\Omega_{t}\right.$ and $\left.\ln \varphi_{t}\right)$ around $\mathrm{E} \phi_{t}=1$. In this case, the steady-state inequality and the expected long-run growth rate of aggregate human capital are given by, respectively (see Appendix A.3),

$$
\begin{aligned}
\sigma^{2} & \approx \frac{\omega^{2}}{1-\beta^{2}} \theta^{2} v^{2} \\
\mathrm{E} \gamma & \approx \ln \psi-\omega(1-\theta) \chi^{2}-\digamma
\end{aligned}
$$

where

$$
\digamma \approx 0.5\left(\sigma^{2} \beta(1-\beta)+\omega(1-\omega) v^{2} \theta^{2}\right)
$$

\footnotetext{
${ }^{10}$ Novales et al. (2009, Ch. 5) use this approach to obtain a steady state in a stochastic economy.
} 
$\mathrm{E} \gamma$ is also the expected long-run growth rate of the economy. ${ }^{11}$. Therefore, the longrun equilibrium of the economy is a balanced growth path, with a constant non-zero level of inequality.

We see from (9) that aggregate volatility has no effect on steady-state inequality, although this may not be the case for growth. Inequality in the long run is the result of individuals' differences in human capital investment decisions as a response to differences in their luck. Idiosyncratic shocks are sources of non-degenerate equilibrium distributions. This is easily seen from (9): if $v^{2}=0$ or $\theta=0$, the steady-state inequality is zero. This is intuitive because if individual households differ only in terms of initial human capital but are similar otherwise, individuals with relatively lower $h_{i 0}$ rapidly accumulate wealth due to their relatively high marginal productivity, which is, in turn, due to diminishing returns to investment. Such an economy features a declining inequality along transition to a steady state, and ends up in a long-run equilibrium characterized by a degenerate human capital and income inequality. With the presence of uninsurable idiosyncratic risks $\left(v^{2} \neq 0\right)$, however, inequality sustains in the long run due to individuals' inability to overcome initial differences in luck.

The long-run equilibrium of inequality depends on the parameters of production and accumulation technologies, including the shock parameter, such as $\alpha, \omega$ and $\theta$. Because the steady-state wealth distribution is mainly determined through the distribution of idiosyncratic shocks $\epsilon_{i t}$, the relative weight of $\epsilon_{i t}$ is an important determinant of the long-run level of inequality.

Proposition 2. The lower the relative weight of idiosyncratic shocks (lower $\theta$ ), the lower the long-run inequality level $\left(\sigma^{2}\right)$ will be.

Proof. From (9a), it is straightforward to see that $\sigma^{2}$ increases in $\theta$.

From (8) and (9), inequality, both during the transition and in steady state, increases in the private factor share $\alpha$ but the effect from the investment elasticity $\omega$ is ambiguous. A higher private factor share benefits disproportionately those individuals with a relatively high level of initial human capital, which eventually leads to higher steady-state inequality. Inequality also decreases with better schooling technologies (higher $\omega$ ) that undermine the intergenerational linkages and encourage

\footnotetext{
${ }^{11}$ To see this, aggregate (2b), using (A.5), which gives $y_{t}=a \varphi_{t} h_{t} e^{0.5 \alpha(\alpha-1) \sigma_{t}^{2}}$. Then, $\mathrm{E} \gamma \equiv$ $\ln y_{t+1}-\ln y_{t}=\ln h_{t+1}-\ln h_{t}$, considering $\mathrm{E} \ln \varphi_{t+1}=\mathrm{E} \ln \varphi_{t}$ and, in the steady state, $\sigma_{t+1}^{2}=$ $\sigma_{t}^{2}=\sigma^{2}$.
} 
households to invest in human capital (see eq. (2c)). ${ }^{12}$ But, at the same time a higher $\omega$ may imply a higher inequality as it affects individuals' response to luck. Because, from (7), $\omega$ is also the elasticity of optimal individual human capital to individual risks. ${ }^{13}$

The term $\digamma \geq 0$ in $(9 \mathrm{~b})$ captures the negative relationship between steady-state inequality and long-run growth. The equality holds if there is no long-run inequality (which is the case if $v^{2}=0$ or $\theta=0$ ). Therefore, both during the transition and in the steady state, inequality has a bad influence on growth. The underlying factors behind such a relationship are the imperfections in the credit market. Diminishing returns to investment imply that relatively poor individuals have a higher marginal product than others. But, since they cannot borrow and invest efficiently due to credit constraints, Pareto efficiency cannot be achieved, as in economies with complete markets. Therefore a higher inequality leads to a greater inefficiency.

Proposition 3. Inequality in terms of differences in human capital wealth and idiosyncratic productivity could have a negative impact on the growth rate of an economy both during transition and in a steady state.

Proof. It is straightforward to see that $\digamma$ and $\digamma_{t}$ increase in $v^{2}$ and $\sigma^{2}$.

Because $\digamma$ also increases in $\theta$, a lower weight in idiosyncratic shocks (lower $\theta$ ) means lower growth via the effect on inequality. But, this could be partly offset, as growth also decreases in the relative weight of aggregate risks $(1-\theta)$. As shown in (9b), there is a negative relationship between growth and aggregate risks in the form of aggregate volatility, though trivial quantitatively. ${ }^{14}$

\subsection{Interactive shocks}

An alternative formulation and a disaggregation of productivity shocks would be for the two shocks to enter the production function interactively. In this case, the $i$ th firm production function, eq. (2b), would take the following form:

$$
y_{i t}=a_{1} \eta_{i t}\left(h_{i t}\right)^{\alpha}\left(h_{t}\right)^{1-\alpha}
$$

\footnotetext{
${ }^{12}$ This is intuitive, as the only way the poor can catch up with the rich, in this economy, is by investing more in human capital.

${ }^{13}$ The parameter $\omega$ may have different interpretations in the literature. Basu and Getachew (2015), for instance, ascribe it to a convex human capital adjustment cost that determines the curvature of the marginal return to investment, whereas Bandyopdhyay and Tang (2011) use the elasticity term $1-\omega$ to represent the quality of parental nurturing.

${ }^{14}$ See Section 5 of the paper.
} 
where

$$
\begin{aligned}
\eta_{i t} & \equiv\left(\phi_{t}\right)^{1-\theta}\left(\epsilon_{i t}\right)^{\theta} \\
a_{1} & \equiv a e^{0.5 v^{2} \theta(1-\theta)}
\end{aligned}
$$

Similar to $\vartheta_{i t}, \eta_{i t}$ is the total productivity shocks faced by the $i$ th individual firm from idiosyncratic $\left(\epsilon_{i t}\right)$ and common shocks $\left(\phi_{t}\right)$, where $\theta$ represents the share of idiosyncratic risks. The exponential term in $a_{1}$ guarantees that idiosyncratic shocks (individuals' luck) cancel out in the aggregate. ${ }^{15}$ The interactions appear even though the two risks are assumed to be statistically independent. In related literature, interactions arise, even if the risks are orthogonal by construction, through multiplying each other in budget constraints (see, for instance, Harenberg and Ludwig, 2014). Such interactions imply that economy-wide risks are likely to exacerbate the effects from individual specific risks. ${ }^{16}$

In this case, the $i$ th individual capital dynamics is derived from $(2 \mathrm{c}),(6 \mathrm{~b})$ and (10):

$$
h_{i t+1}=\psi_{1} \eta_{i t}^{\omega}\left(h_{t}\right)^{1-\beta}\left(h_{i t}\right)^{\beta}
$$

where $\psi_{1} \equiv b\left(\varkappa a_{1}\right)^{\omega}$.

From (11), one sees immediately that human capital elasticity is independent of shocks. Basically, (11) has the same form as (7) where the inter-generational elasticities are similar.

The steady state and the dynamics of inequality and aggregate capital can be derived in a similar fashion as earlier. Firstly, taking the log and then the variance of (11) simply gives the dynamics of inequality. Then, aggregating through (11) yields the dynamics of aggregate human capital (see Appendix A.1 for details):

$$
\begin{aligned}
\sigma_{t+1}^{2} & =\beta^{2} \sigma_{t}^{2}+\omega^{2} \theta^{2} v^{2} \\
\mathrm{E} \gamma_{t+1} & \equiv \ln \psi-0.5(1-\theta) \omega \chi^{2}-\Phi_{t}
\end{aligned}
$$

\footnotetext{
${ }^{15} \mathrm{E}_{i}\left[a_{1} \eta_{i t}\right]=a\left(\phi_{t}\right)^{1-\theta}$ since $\mathrm{E}_{i}\left(\epsilon_{i t}\right)^{\theta} e^{0.5 v^{2} \theta(1-\theta)}=1$. See Appendix A.1 for details on aggregation.

${ }^{16}$ Harenberg and Ludwig (2014) argue that interactions between idiosyncratic and aggregate shocks have important implications for welfare effects of social security; they increase the welfare benefits from insurance.
} 
where

$$
\Phi_{t} \equiv 0.5\left(\sigma_{t}^{2} \beta(1-\beta)+v^{2} \omega \theta^{2}(1-\omega)\right)
$$

and $\mathrm{E} \gamma_{t+1}$ represents the expected growth rate of capital between periods $t$ and $t+1$.

Many of the previous analyses and results do not change when the shocks enter interactively. Similar to (8), eq. (12) consists of the dynamic system of capital and inequality, which characterizes the transitional dynamics of the economy. Inequality is history dependent whereas the dynamics of aggregate capital solely depends on the evolution of inequality.

From (12), steady-state inequality and the economy's expected long-run growth rate are derived:

$$
\begin{aligned}
\sigma^{2} & =\frac{\omega^{2}}{1-\beta^{2}} v^{2} \theta^{2} \\
\mathrm{E} \gamma & =\ln b(\varkappa a)^{\omega}-0.5((1-\theta) \omega) \chi^{2}-\Phi
\end{aligned}
$$

where

$$
\Phi \equiv 0.5\left(\sigma^{2} \beta(1-\beta)+\omega v^{2} \theta^{2}(1-\omega)\right)
$$

Similar to $\digamma$ in $(9), \Phi \geq 0$ captures the growth inequality trade-offs while $\Phi=0$ if $v^{2}=0$. Moreover, aggregate risks have a negative direct effect on growth while idiosyncratic risks have an indirect negative influence on growth via the effect on inequality. If either of these risks are not involved (if $\theta=1$ or $\theta=0$ ), (12) and (13) exactly revert to (8) and (9), respectively. Apparently, even when $\theta \in(0,1)$ they are approximately the same.

In the case of $\theta=0, \sigma^{2}$ has a degenerate distribution for the same reason as mentioned earlier. Without insured idiosyncratic risks, individuals with relatively lower initial capital rapidly accumulate wealth due to their relatively high marginal productivity, leading to a declining inequality along the transitional path, and, eventually, to a degenerate human capital distribution. A lower weight of idiosyncratic shocks implies lower long-run inequality, which in turn implies higher growth.

\subsection{Welfare effects}

While growth and inequality are important macroeconomic variables, the economic significance of these shocks are basically judged in terms of their impacts on social welfare. Given that $U_{i 0}$ is the discounted sum of individual utility functions 
across its dynasty, its aggregation (across the entire population) leads to the discounted aggregate welfare: $W_{0}=\int_{0}^{1} V_{i 0} d i$ where $V_{i 0}=\max U_{i 0}$. Then, the expected aggregate welfare is given by (see Appendix B for details), for interactive shocks,

$$
\mathrm{E} W_{0}=Z_{0}+B\left(\ln h_{0}-0.5 \sigma_{0}^{2}\right)-0.5 D(1-\rho)^{-1}\left((1-\theta) \chi^{2}+\theta^{2} v^{2}\right)
$$

where $Z_{0}, B$ and $D$ are given by

$$
\begin{aligned}
Z_{0} & \equiv(1-\rho)^{-1}\left(D \ln \left(h_{0}^{1-\alpha} a D^{-1}\right)+\rho B \ln \left(b(D-1)^{\omega}\right)\right) \\
B & \equiv \frac{\alpha}{1-\rho(\alpha \omega+1-\omega)} \\
D & \equiv 1+\omega \rho B
\end{aligned}
$$

In the steady state, $\sigma^{2}$ is given by (13a).

Therefore, both aggregate and idiosyncratic risks and inequality play a role in welfare. The last term in eq. (14) captures the welfare cost of risks while the second shows the welfare cost of inequality. Given that $v^{2}$ appears more than one time in eq. (14), both in the second (via its effect on $\sigma^{2}$ ) and the last terms, it is intuitive that idiosyncratic risks are more important than aggregate risks. We see this is actually the case in Section 5, where we study the relative significance of these two shocks and the weight attached to them quantitatively.

Proposition 4. (i) Steady-state inequality, aggregate and idiosyncratic risks have a negative influence on welfare. (ii) Idiosyncratic risks impact welfare both directly and indirectly (via their impact on inequality).

Proof. (i) From (14), it is straightforward to see that E $W_{0}$ decreases in $\sigma^{2}, \chi^{2}$ and $v^{2}$. (ii) From (13a), $\sigma^{2}$ increases in $v^{2}$.

\section{Redistribution policies and idiosyncratic risks}

In this section, we introduce progressive income taxation and a redistribution of income. Such policies could serve as social insurance against idiosyncratic risks, giving the government some form of control over individual risks (Krueger and Ludwig, 2016). ${ }^{17}$

\footnotetext{
${ }^{17}$ As seen below, in the extreme case where the government makes a complete redistribution of income, idiosyncratic risks fully disappear while aggregate risks remain unaffected.
} 
Following Benabou (2002), suppose the government redistributes income loglinearly as follows:

$$
\widehat{y}_{i t}=\left(y_{i t}\right)^{1-\tau}\left(\widetilde{y}_{t}\right)^{\tau}
$$

where $\widehat{y}_{i t}$ is the disposable income of the $i$ th agent, after tax and redistribution. $\widetilde{y}_{t}$ is the threshold income, which will be determined later on, and $\tau$ represents the marginal tax rate. The sign of $\tau$ determines the progressivity/regressivity of the tax schedule. We let $\tau \in(0,1)$, in line with the empirical literature, which implies a progressive tax schedule.

The budget constraint is thus given by,

$$
\widehat{y}_{i t}=c_{i t}+s_{i t}
$$

where the household allocates its after-tax and after-redistribution income between consumption and saving.

In this case, the individual optimal solution is given by (see Appendix $\mathrm{C}$ for details)

$$
\begin{aligned}
c_{i t} & =(1-\tau)(1-\varkappa) \widehat{y}_{i t} \\
s_{i t} & =(1-\tau) \varkappa \widehat{y}_{i t}
\end{aligned}
$$

Substituting (17b) into (2c), and using (10), (C.27) and (C.28), yield the following optimal individual human capital accumulation function:

$$
h_{i t+1}=(1-\tau)^{\omega} \psi\left(\epsilon_{i t}\right)^{\theta(1-\tau) \omega}\left(\phi_{t}\right)^{(1-\theta) \omega}\left(h_{i t}\right)^{\varrho}\left(h_{t}\right)^{1-\varrho} e^{p}
$$

where

$$
\begin{aligned}
& \varrho \equiv 1+\omega(\alpha(1-\tau)-1) \\
& p \equiv 0.5 \tau \omega \alpha \sigma_{t}^{2}(2 \alpha-\tau \alpha-1)+0.5 v^{2}(1-\tau) \theta \omega(1-\theta+\theta \tau)
\end{aligned}
$$

Eq. (18) is both comparable and contrastable with eq. (11). Firstly, (18) reduces to (11) if $\tau=0$. $\varrho$ represents intergenerational linkages at an individual level, similar to $\beta$ in eq. (11). It depends on the structure of production and human capital accumulation technologies and is the main determinant of the evolution of inequality. But it also depends on policy. Secondly, there is a new term $\exp (p)$ that declares a relationship between today's inequality and the next period of individual human 
capital wealth. Such a relationship arises because the government's policy of taxation and redistribution of income depends on current aggregate income, which in turn is a function of current inequality. Thirdly, the weight associated to individual risks is now effectively decreased by $\tau \theta$. Idiosyncratic risks disappear completely if $\tau=1$ whereas there would not be any change with regard to aggregate risks. This shows that, even though individual risks are basically functions of structural parameters, the government could influence them via the type of social insurance scheme that it provides.

Taking the log and the variance of (18), we obtain the dynamic equation that characterizes the evolution of inequality,

$$
\sigma_{t+1}^{2}=(\theta(1-\tau) \omega)^{2} v^{2}+\varrho^{2} \sigma_{t}^{2}
$$

Eq. (19) is again similar to (12a) without government intervention. Given $\varrho<$ 1 , the dynamics in (19) is stable and converges monotonically to a finite steady state. Apparently, the redistribution of income has a positive effect on distributional dynamics. Particularly, for a given $\sigma_{t}^{2}, \sigma_{t+1}^{2}$ decreases in $\tau$.

By aggregating (18), and following similar procedures as in Appendix A.1, we obtain the growth rate of the economy:

$$
\mathrm{E} \gamma_{t+1}=\ln b((1-\tau) \varkappa a)^{\omega}-0.5(1-\theta) \omega \chi^{2}-\varpi_{t}
$$

where

$$
\begin{aligned}
\varpi_{t} & \equiv 0.5 \tau \omega \sigma_{t}^{2} \alpha(1-2 \alpha+\alpha \tau)+0.5 \sigma_{t}^{2} \varrho(1-\varrho) \\
& +0.5 v^{2}(1-\tau)^{2} \theta^{2} \omega(1-\omega)
\end{aligned}
$$

Steady-state inequality and expected aggregate growth are then given by, respectively, considering (19) and (20):

$$
\begin{aligned}
\sigma^{2} & =(v \theta(1-\tau) \omega)^{2} /\left(1-\varrho^{2}\right) \\
\mathrm{E} \gamma & =\ln b((1-\tau) \varkappa a)^{\omega}-0.5(1-\theta) \omega \chi^{2}-\varpi
\end{aligned}
$$

Thus, $\varpi$ captures the effects of inequality on aggregate capital accumulation. It is likely that $\varpi>0$ that implies a negative relation between inequality and growth. However, we do not necessarily discard the possibility of a negative $\varpi$. The last two terms are positive whereas the first term is positive for plausible parameter values 
$(\alpha \leq 0.5)$.

The positive effects of redistribution on inequality also holds in a steady state. But the same cannot be said about growth. Redistribution of income could have a positive effect on the expected growth rate via its effects of mitigating inequality. However, it also hurts individual investment in human capital, through distorting individual saving and consumption decisions, as shown in eq. (17).

\section{Calibration}

In this section, we numerically study the model in order to gain further insight on the effects of various risk factors on inequality, growth and welfare. We first calibrate eqs. (13), (14), (21) and (C.33) using standard values, which reasonably reflect actual economies. We set the discount factor, $\rho$, at 0.96 , a typical value in macroeconomic models. We let $b$ simply take unity while we choose $a$ targeting a long-run growth rate of about $1.8 \%$. This matches the average annual long-run growth rate of the USA's economy for the last hundred years. The share of capital, $\alpha$, is set at its standard value, 0.33. For $\omega$, we take Glomm's (1997) estimate of 0.8. Regarding risks, following Turnovsky and Bianconi (2005), we consider a 2.5\% aggregate risks and a 0.4 standard deviation for idiosyncratic risks (see also Getachew and Turnovsky, 2015). According to Pischke (1995), the standard deviation for idiosyncratic shocks is around 6.5 times that of aggregate output. We use that to calibrate the respective values for the weights of these shocks, which implies a slightly higher than 0.85 value for $\theta$. Table 1 below summarizes the calibration of the parameters. The baseline value for the tax rate, $\tau$, is set at 0.05 while we experiment using a range of values between 0 and 1 .

\section{TABLE 1 HERE}

Table 2 shows the effects of eliminating aggregate and idiosyncratic shocks on welfare, inequality and growth. The first column displays the effects on welfare. Idiosyncratic risks are by far the most important determinants of welfare. Totally eliminating the idiosyncratic shocks leads to more than a $16 \%$ increase in welfare. In contrast, eliminating aggregate shocks have a trivial impact on welfare $(<0.1 \%)$. The lower the weights of idiosyncratic risks, the smaller the welfare costs associated to the risks become. Eliminating the risks (from their baseline value $\theta=0.85$ ) could lead to a more than $11 \%$ welfare gain. In general, the results are in line with recent literature that studies the effects of risks on macroeconomic performance, ${ }^{18}$ although

\footnotetext{
${ }^{18}$ For instance, Atkeson and Phelan (1994), Storesletten et al. (2001), Krebs (2003), Turnovsky
} 
this literature (with the exception of Turnovsky and Bianconi, 2005) often focuses on either idiosyncratic or aggregate shocks.

\section{TABLE 2 HERE}

Idiosyncratic risks are also important determinants of inequality and growth. The second column in Table 2 shows that inequality declines significantly as the weights attached to these shocks decline. If $\theta$ is smaller by 0.20 points from its benchmark, for instance, inequality will be lower by $33 \%$. As argued earlier, idiosyncratic risks are the main determinants of long-run inequality. Initial wealth inequality disappears in the absence of such risks due to diminishing returns to investment where households with a low level of wealth grow quickly due to their relatively high marginal productivity. Idiosyncratic risks have also a strong effect on long-run growth. For instance, fully eliminating idiosyncratic shocks could lead to a $2.90 \%$ points increase in the long-run growth rate, which is quite phenomenal compared to the insignificant effects resulting from eliminating aggregate shocks.

Table 3 illustrates a similar analysis. But this time there is a redistribution of income at a rate of $\tau=0.05$. Fully eliminating risks will have similar effects on welfare, growth and inequality while idiosyncratic risks are the most important determinants of these variables. But the magnitude of such effects are relatively smaller as government interventions have already accounted for parts of the idiosyncratic risks. Apparently, steady-state inequality is lower for all values of $\theta$ with policy interventions.

\section{TABLE 3 HERE}

Table 4 shows the effects of redistribution on welfare, inequality and growth for benchmark values. Redistribution of income leads to welfare gains and decreases in inequality but at the same time it decreases long-run growth. For instance, a 10\% point rise in a progressive tax rate from its baseline value will increase welfare by about $2.08 \%$ and will decrease inequality by more than $22 \%$, but it will also result in a growth loss of more than $8 \%$ point.

\section{TABLE 4 HERE}

and Bianconi (2005) and Krusell et al. (2009) found a substantial welfare cost of the business cycle related to idiosyncratic shocks. 


\section{Conclusion}

The paper has developed an endogenous growth model with incomplete markets where productivity shocks were disaggregated into idiosyncratic and aggregate shocks. Uninsured idiosyncratic risks are by far the most important determinants of inequality, growth and welfare. Such risks determine the long-run distribution of income due to the inability individuals to overcome their differences in luck in the presence of such risks. A lower weight on the idiosyncratic shocks (vis-à-vis aggregate shocks) leads to a lower steady-state inequality, a higher growth and welfare. Aggregate risks, on the contrary, do not impact inequality, as the risks are commonly shared among individuals. But, they have a negative influence on growth and welfare, though trivial quantitatively. A redistribution of income could serve as social insurance against idiosyncratic risks and hence could increase welfare and decrease inequality. However, it could also negatively impact growth due to its distortionary effect on individual savings and consumption decisions. A future extension of the work would be to endogenize individual risks that would leave more room for other policy interventions. 


\section{Appendix}

\section{A. Aggregation, the household problem and approximation}

\section{A.1. Inequality and growth dynamics}

Recall first that $\epsilon_{i t}$ and $h_{i t}$ are assumed to have log-normal distributions: $\ln \epsilon_{i t} \sim$ $N\left(\ln -v^{2} / 2, v^{2}\right)$ and $\ln h_{i t} \sim N\left(\mu_{t}, \sigma_{t}^{2}\right)$. Then,

$$
\begin{aligned}
\mathrm{E}_{i} h_{i t} & \equiv h_{t}=e^{\mu_{t}+0.5 \sigma_{t}^{2}} \\
\operatorname{var}_{i} h_{i t} & =\left(h_{t}\right)^{2}\left(e^{\sigma_{t}^{2}}-1\right) \\
\operatorname{var}_{i} \epsilon_{i t} & =\left(e^{v^{2}}-1\right)
\end{aligned}
$$

where $\mathrm{E}_{i}$ and $\operatorname{var}_{i}$ represent the cross-sectional expectation (average) and variance, respectively. If $h_{i t}$ is log-normal, then $\left(h_{i t}\right)^{x}$ is also log-normal for any constant $x$ :

$$
\ln \left(h_{i t}\right)^{x} \sim N\left(x \mu_{t}, x^{2} \sigma_{t}^{2}\right)
$$

Thus, considering (A.1), (A.2) and (A.4), we have:

$$
\begin{aligned}
\mathrm{E}_{i}\left(h_{i t}\right)^{x} & =\left(h_{t}\right)^{x} e^{0.5 \sigma_{t}^{2} x(x-1)} \\
\operatorname{var}_{i}\left(h_{i t}\right)^{x} & =\left(h_{t}\right)^{2 x} e^{\sigma_{t}^{2} x(x-1)}\left(e^{x^{2} \sigma_{t}^{2}}-1\right)
\end{aligned}
$$

Similarly,

$$
\mathrm{E}_{i}\left(\epsilon_{i t}\right)^{x}=e^{0.5 \sigma_{t}^{2} x(x-1)}
$$

From this, aggregating (7) is straightforward. First, rewrite (7) as

$$
\left(h_{i t+1}\right)^{\varsigma}=\varkappa a b^{\varsigma}\left(h_{i t}\right)^{\beta \varsigma} \vartheta_{i t}\left(h_{t}\right)^{1-\alpha}
$$

where $\varsigma \equiv 1 / \omega$. Then, aggregate both sides of (A.8),

$$
\mathrm{E}_{i}\left(h_{i t+1}\right)^{\varsigma}=\varkappa a b^{\varsigma}\left(h_{t}\right)^{1-\alpha} \mathrm{E}_{i}\left[\left(h_{i t}\right)^{\beta \varsigma} \vartheta_{i t}\right]
$$

Then, considering (A.5), we obtain 


$$
\left(h_{t+1}\right)^{\varsigma} e^{0.5 \sigma_{t+1}^{2}(\varsigma-1) \varsigma}=\varkappa a b^{\varsigma}\left(h_{t}\right)^{1-\alpha}\left(h_{t}\right)^{\beta \varsigma} e^{0.5 \sigma_{t}^{2} \beta \varsigma(\beta \varsigma-1)} \varphi_{t}
$$

where $\varphi_{t} \equiv(1-\theta) \phi_{t}+\theta$, since $\vartheta_{i t}$ and $h_{i t}$ are independent and $\mathrm{E}_{i} \epsilon_{i t}=1$.

To obtain (8a), first take the variance from both sides of (A.8),

$$
\operatorname{var}_{i}\left(h_{i t+1}\right)^{\varsigma}=(\varkappa a)^{2} b^{2 \varsigma}\left(h_{t}\right)^{2(1-\alpha)} \operatorname{var}_{i}\left[\left(h_{i t}\right)^{\beta \varsigma} \vartheta_{i t}\right]
$$

On the left side of (A.10), considering (A.6), we have:

$$
\operatorname{var}_{i}\left(h_{i t+1}\right)^{\varsigma}=\left(h_{t+1}\right)^{2 \varsigma} e^{\sigma_{t}^{2} \varsigma(\varsigma-1)}\left(e^{\varsigma^{2} \sigma_{t+1}^{2}}-1\right)
$$

We can compute the right side of (A.10) as follows, using (A.3), (A.5) and (A.6): ${ }^{19}$

$$
\begin{aligned}
\operatorname{var}_{i}\left[\left(h_{i t}\right)^{\beta \varsigma} \vartheta_{i t}\right] & =\left(\mathrm{E}_{i} \vartheta_{i t}\right)^{2} \operatorname{var}_{i}\left[\left(h_{i t}\right)^{\beta \varsigma}\right]+\operatorname{var}_{i} \vartheta_{i t}\left(\left(\mathrm{E}_{i}\left(h_{i t}\right)^{\beta \varsigma}\right)^{2}+\operatorname{var}_{i}\left(h_{i t}\right)^{\beta \varsigma}\right) \\
& =\left(h_{t}\right)^{2 \beta \varsigma} e^{\sigma_{t}^{2} \beta \varsigma(\beta \varsigma-1)}\left(e^{(\beta \varsigma)^{2} \sigma_{t}^{2}}\left(\left(\varphi_{t}\right)^{2}+\theta^{2}\left(e^{v^{2}}-1\right)\right)-\left(\varphi_{t}\right)^{2}\right)
\end{aligned}
$$

Combining (A.10), (A.11) and (A.12), and using (A.9), we obtain:

$$
e^{\varsigma^{2} \sigma_{t+1}^{2}}=e^{(\beta \varsigma)^{2} \sigma_{t}^{2}}\left(1+\left(\theta / \varphi_{t}\right)^{2}\left(e^{v^{2}}-1\right)\right)
$$

which is equivalent to (8a). Then, using (8a) and (A.9), we can easily derive (8b).

To obtain (12b), aggregate both sides of (11), which yields:

$$
\mathrm{E}_{i} h_{i t+1}=b(\varkappa a)^{\omega}\left(h_{t}\right)^{1-\beta} \mathrm{E}_{i}\left(h_{i t}\right)^{\beta}\left(\phi_{t}\right)^{\omega(1-\theta)} \mathrm{E}_{i}\left(\epsilon_{i t}\right)^{\theta \omega} e^{0.5 v^{2} \theta \omega(1-\theta)}
$$

Then, apply (A.5) and (A.7).

\footnotetext{
${ }^{19}$ For two independent random variables $x$ and $y$, the variance of their product is given by:

$$
\operatorname{var}[x y]=(\mathrm{E}[x])^{2} \operatorname{var}[y]+(\mathrm{E}[y])^{2} \operatorname{var}[x]+\operatorname{var}[y] \operatorname{var}[x]
$$
}




\section{A.2. Solution for the household problem}

The first-order conditions for the $i$ th individual maximization of (1), subject to (2), associated to the Lagrangian ( $\mathrm{E}$ ),

$$
\mathrm{L}=\mathrm{E}_{t} \sum_{t=0}^{\infty} \rho^{t}\left\{\ln c_{i t}+\lambda_{i t}\left(y_{i t}-c_{i t}-\left(h_{i t+1}\right)^{1 / \omega}\left(h_{i t}\right)^{(\omega-1) / \omega} b^{-1 / \omega}\right)\right\}
$$

are given by,

$$
\begin{aligned}
0 & =-\lambda_{i t}+\left(c_{i t}\right)^{-1} \\
\lambda_{i t} \omega^{-1} s_{i t} & =\rho \mathrm{E}_{t}\left[\lambda_{i t+1}\left((1-\omega) \omega^{-1} s_{i t+1}+\alpha y_{i t+1}\right)\right]
\end{aligned}
$$

Then, the Euler equation becomes:

$$
\left(c_{i t}\right)^{-1} s_{i t}=\rho \mathrm{E}_{t}\left[\left(c_{i t+1}\right)^{-1}\left((1-\omega) s_{i t+1}+\omega \alpha y_{i t+1}\right)\right]
$$

Applying undetermined coefficient methods in (2a) and (A.17) gives the solutions in (6).

\section{A.3. Approximation}

A loglinear approximation of the terms $\ln \varphi_{t}$ and $\Omega_{t}$ in eq. (8) around $\mathrm{E} \phi_{t}=1$ yields:

$$
\begin{aligned}
\ln \varphi_{t} & \approx(1-\theta) \ln \phi_{t} \\
\Omega_{t} & \equiv \ln \left(1+z \varphi_{t}^{-2}\right) \approx \ln (1+z)-\frac{2 z}{1+z}(1-\theta) \ln \phi_{t}
\end{aligned}
$$

It follows that

$$
\begin{aligned}
\mathrm{E} \Omega_{t} & \approx \ln (1+z)+\chi^{2}(1-\theta) z /(1+z) \\
& \approx \ln (1+z)
\end{aligned}
$$

In arriving at (A.18b), we use the fact that the last term in (A.18a) is almost zero, for reasonable parametric values. Using our calibrated values in Section 5, for instance, $\chi^{2}(1-\theta) z /(1+z) \approx 1.0095 \times 10^{-5}$. Given that $\exp \left(v^{2}\right)-1 \approx v^{2}$, we can also 
further simplify (A.18b):

$$
\ln (z+1) \approx z \equiv \theta^{2}\left(\exp \left(v^{2}\right)-1\right) \approx \theta^{2} v^{2}
$$

\section{B. Welfare}

Individual welfare could easily be derived by applying dynamic programming to the problem. Thus from (1), (2c) and (10), the Bellman equation is given by

$$
V(h, \eta)=\max _{c}\left\{\ln c+\rho \mathrm{E}\left[V\left(h^{\prime}, \eta^{\prime}\right) \mid \eta\right]\right\}
$$

where $\mathrm{E}[. \mid \eta]$ represents the expectation conditional on the current value of $\eta$. $V$ is the value function associated to the $i$ th individual. $h^{\prime}$ and $\eta^{\prime}$ represent human capital and risk factors in the next period while $c$ is the person's current consumption. Substituting (2a) and (10) into (2c), we get:

$$
\begin{aligned}
h^{\prime} & \equiv b h^{1-\omega}\left(a_{1} \eta h^{\alpha} \bar{h}^{1-\alpha}-c\right)^{\omega} \\
c & \equiv a_{1} \eta h^{\alpha} \bar{h}^{1-\alpha}-\left(h^{\prime} /\left(b h^{1-\omega}\right)\right)^{1 / \omega}
\end{aligned}
$$

where $h$ and $\bar{h}$ represent the current individual and aggregate capitals, respectively. Substituting (B.20b) into the Bellman equation, one gets:

$$
V(h, \eta)=\max _{h^{\prime}}\left\{\ln \left(a_{1} \eta h^{\alpha} \bar{h}^{1-\alpha}-\left(h^{\prime} /\left(b h^{1-\omega}\right)\right)^{1 / \omega}\right)+\rho \mathrm{E}\left[V\left(h^{\prime}, \eta^{\prime}\right) \mid \eta\right]\right\}
$$

The FOC:

$$
\rho \mathrm{E}\left[V_{h^{\prime}}\left(h^{\prime}, \eta^{\prime}\right) \mid \eta\right]=\frac{\left(h^{\prime} /\left(b h^{1-\omega}\right)\right)^{1 / \omega}}{\omega h^{\prime}\left(a_{1} \eta h^{\alpha} \bar{h}^{1-\alpha}-\left(h^{\prime} /\left(b h^{1-\omega}\right)\right)^{1 / \omega}\right)}
$$

where $V_{h^{\prime}}=\partial V\left(h^{\prime}, \eta^{\prime}\right) / \partial h^{\prime}$. We guess the value function as follows:

$$
V(h, \eta)=A+B \ln h+D \ln \eta
$$

where $A, B$ and $D$ are undetermined coefficients. Substitute this into the above to get: 


$$
h^{\prime}=b\left(\frac{B \rho \omega a_{1} \eta}{1+\rho B \omega}\right)^{\omega} h^{\alpha \omega+1-\omega} \bar{h}^{(1-\alpha) \omega}
$$

The solution for the undetermined coefficients, considering (B.21) (B.23) and (B.24) are given by:

$$
\begin{aligned}
(1-\rho) A & =D \ln \left(\bar{h}^{(1-\alpha)} a_{1} D^{-1}\right)+\rho B \ln \left(b(D-1)^{\omega}\right)+\rho D \mathrm{E}\left[\ln \eta^{\prime} \mid \eta\right] \\
B & =\frac{\alpha}{1-\rho(\alpha \omega+1-\omega)} \\
D & =1+\omega \rho B
\end{aligned}
$$

For the interactive shocks, it is straightforward that $\mathrm{E}\left[\ln \eta^{\prime} \mid \eta\right]=-0.5\left((1-\theta) \chi^{2}+\theta v^{2}\right) .{ }^{20}$

Substituting $B$ into (B.24), we get easily the solution to the problem with respect to the individual's optimal human capital accumulation:

$$
h_{i t+1}=\psi_{1} \eta_{i t}^{\omega} h_{i t}^{\alpha \omega+1-\omega} h_{t}^{(1-\alpha) \omega}
$$

where $\psi_{1} \equiv b\left(\frac{\alpha \rho \omega a_{1}}{1-\rho(1-\omega)}\right)^{\omega}$. One confirms that this is similar to $(11)$.

Therefore, the $i$ th individual welfare becomes

$$
V_{i 0}=A_{0}+B \ln h_{i 0}+D \ln \eta_{i 0}
$$

where

$$
A_{0}=(1-\rho)^{-1}\left(\begin{array}{c}
D \ln \left(h_{0}^{(1-\alpha)} a_{1} D^{-1}\right)+\rho B \ln \left(b(D-1)^{\omega}\right) \\
-0.5 \rho D\left((1-\theta) \chi^{2}+\theta v^{2}\right)
\end{array}\right)
$$

Finally, the expected (trend) aggregate welfare is given by

$$
\mathrm{E} W_{0}=\mathrm{E} \int_{0}^{1} V_{i 0} d i=A_{0}+B \int_{0}^{1} \ln h_{i 0}+D \mathrm{E} \int_{0}^{1} \ln \eta_{i 0}
$$

which leads to eq. (14) in the text.

\footnotetext{
${ }^{20}$ But even for additive shocks similar results can be obtained with (loglinear) approximation. That is, $\ln \vartheta_{i t} \equiv \ln \left((1-\theta) \phi_{t}+\theta \epsilon_{i t}\right) \approx(1-\theta) \ln \phi_{t}+\theta \ln \epsilon_{i t}$ when it is approximated around $\mathrm{E} \phi_{t}=\mathrm{E} \epsilon_{i t}=1$.
} 


\section{Redistribution}

First determine the threshold income $\widetilde{y}_{t}$ using the following relation:

$$
\int_{0}^{1} \widehat{y}_{i t} d i=\int_{0}^{1} y_{i t} d i \equiv y_{t}
$$

That is, the aggregate post-tax and -redistribution income is equal to the aggregate pre-tax and -redistribution income, $y_{t}$.

Combining (10), (15) and (C.25) gives

$$
\widetilde{y}_{t}=y_{t} e^{0.5(1-\tau)\left(v^{2} \theta^{2}+\alpha^{2} \sigma_{t}^{2}\right)}
$$

And from (15) and (C.26), we have

$$
\widehat{y}_{i t}=\left(y_{i t}\right)^{1-\tau}\left(y_{t}\right)^{\tau} e^{0.5(1-\tau)\left(v^{2} \theta^{2}+\alpha^{2} \sigma_{t}^{2}\right) \tau}
$$

We can also aggregate (10) to get the aggregate output:

$$
y_{t}=\left(\phi_{t}\right)^{(1-\theta)} a h_{t} e^{0.5(\alpha-1) \alpha \sigma_{t}^{2}}
$$

The FOC for the $i$ th individual maximization of (1), subject to (2c), (10), (16), and (C.27), associated to the Lagrangian (Ł),

$$
\mathrm{E}=\mathrm{E}_{t} \sum_{t=0}^{\infty} \rho^{t}\left\{\ln c_{i t}+\lambda_{i t}\left(\widehat{y}_{i t}-c_{i t}-\left(h_{i t+1}\right)^{1 / \omega}\left(h_{i t}\right)^{(\omega-1) / \omega} b^{-1 / \omega}\right)\right\}
$$

are given by,

$$
\begin{aligned}
0 & =-\lambda_{i t}+\left(c_{i t}\right)^{-1} \\
\lambda_{i t} \omega^{-1} s_{i t} & =\rho \mathrm{E}_{t}\left[\lambda_{i t+1}\left((1-\omega) \omega^{-1} s_{i t+1}+(1-\tau) \alpha \widehat{y}_{i t+1}\right)\right]
\end{aligned}
$$

The Euler equation then becomes:

$$
\left(c_{i t}\right)^{-1} s_{i t}=\rho \mathrm{E}_{t}\left[\left(c_{i t+1}\right)^{-1}\left((1-\omega) s_{i t+1}+(1-\tau) \omega \alpha \widehat{y}_{i t+1}\right)\right]
$$

Applying undetermined coefficient methods in (16) and (C.32) gives the solutions in (17).

In deriving the expected welfare with a redistribution of income, we follow the 
steps in the preceding section:

$$
\mathrm{E} \bar{W}_{0}=\bar{Z}_{0}+\bar{B}\left(\ln h_{0}-0.5 \sigma_{0}^{2}\right)-0.5(1-\rho)^{-1} \bar{D}\left((1-\theta) \chi^{2}+(1-\tau) \theta^{2} v^{2}\right)
$$

where

$$
\begin{aligned}
\bar{Z}_{0} & \equiv(1-\rho)^{-1}\left(\bar{D} \ln \left(h_{0}^{1-\alpha(1-\tau)} n \bar{D}^{-1}\right)+\rho B \ln \left(b(\bar{D}-1)^{\omega}\right)\right) \\
\bar{B} & \equiv \frac{\alpha(1-\tau)}{1-\rho(\alpha(1-\tau) \omega+1-\omega)} \\
\bar{D} & \equiv 1+\omega \rho \bar{B} \\
n & \equiv a \exp \left(0.5(\alpha-1) \tau \alpha \sigma_{t}^{2}+0.5(1-\tau)\left(v^{2} \theta^{2}+\alpha^{2} \sigma_{t}^{2}\right) \tau\right)
\end{aligned}
$$

\section{Acknowledgements}

The author is grateful to Gerhard Glomm, Parantap Basu, Zhiyun Li, Dambala Gelo, anonymous referees and the associate editor for their useful comments on an earlier version of the paper. The usual disclaimer applies.

\section{References}

Angeletos, G.-M., Calvet, L.-E., 2006. Idiosyncratic production risk, growth and the business cycle. Journal of Monetary Economics 53 (6), 1095-1115.

Atkeson, A., Phelan, C., April 1994. Reconsidering the costs of business cycles with incomplete markets. Working Paper 4719, National Bureau of Economic Research.

Badinger, H., 2010. Output volatility and economic growth. Economics Letters 106 (1), 15-18.

Bandyopadhyay, D., Tang, X., 2011. Parental nurturing and adverse effects of redistribution. Journal of Economic Growth 16 (1), 71-98.

Banerjee, A. V., Newman, A. F., 1993. Occupational choice and the process of development. The Journal of Political Economy 101 (2), 274-298.

Basu, P., Getachew, Y., 2015. An adjustment cost model of social mobility. Journal of Macroeconomics 44, $177-190$. 
Becker, G. S., Tomes, N., 1979. An equilibrium theory of the distribution of income and intergenerational mobility. The Journal of Political Economy 87 (6), 11531189 .

Benabou, R., 2000. Unequal societies: Income distribution and the social contract. The American Economic Review 90 (1), 96-129.

Benabou, R., 2002. Tax and education policy in a heterogeneous-agent economy: What levels of redistribution maximize growth and efficiency? Econometrica $70(2), 481-517$.

Blackburn, K., Galindev, R., 2003. Growth, volatility and learning. Economics Letters $79(3), 417-421$.

Blackburn, K., Varvarigos, D., 2008. Human capital accumulation and output growth in a stochastic environment. Economic Theory 36 (3), 435-452.

Breen, R., Garcia-Penalosa, C., 2005. Income inequality and macroeconomic volatility: An empirical investigation. Review of Development Economics 9 (3), 380398.

Checchi, D., Garcia-Penalosa, C., 2004. Risk and the distribution of human capital. Economics Letters 82 (1), 53-61.

Foerster, A. T., Sarte, P.-D. G., Watson, M. W., 2011. Sectoral versus aggregate shocks: A structural factor analysis of industrial production. Journal of Political Economy 119 (1), 1-38.

Gabaix, X., 2011. The granular origins of aggregate fluctuations. Econometrica $79(3), 733-772$.

Galor, O., Zeira, J., 1993. Income distribution and macroeconomics. The Review of Economic Studies 60 (1), 35-52.

Garcia-Penalosa, C., Turnovsky, S. J., 2005. Production risk and the functional distribution of income in a developing economy: tradeoffs and policy responses. Journal of Development Economics 76 (1), 175-208.

Getachew, Y. Y., 2010. Public capital and distributional dynamics in a two-sector growth model. Journal of Macroeconomics 32 (2), 606-616.

Getachew, Y. Y., 2012. Distributional effects of public policy choices. Economics Letters 115 (1), 56-59. 
Getachew, Y. Y., Turnovsky, S. J., 2015. Productive government spending and its consequences for the growth-inequality tradeoff. Research in Economics 69 (4), $621-640$.

Glomm, G., 1997. Parental choice of human capital investment. Journal of Development Economics 53 (1), 99-114.

Harenberg, D., Ludwig, A., 2014. Social Security and the Interactions Between Aggregate and Idiosyncratic Risk. CER-ETH Economics working paper series 14/193, CER-ETH - Center of Economic Research (CER-ETH) at ETH Zurich.

Horvath, M., 1998. Cyclicality and sectoral linkages: Aggregate fluctuations from independent sectoral shocks. Review of Economic Dynamics 1 (4), 781-808.

Imbs, J., 2007. Growth and volatility. Journal of Monetary Economics 54 (7), 18481862.

Krebs, T., 2003. Growth and welfare effects of business cycles in economies with idiosyncratic human capital risk. Review of Economic Dynamics 6 (4), $846-$ 868.

Krueger, D., Ludwig, A., 2016. On the optimal provision of social insurance: Progressive taxation versus education subsidies in general equilibrium. Journal of Monetary Economics 77, $72-98$.

Krusell, P., Mukoyama, T., Sahin, A., Anthony A. Smith, J., 2009. Revisiting the Welfare Effects of Eliminating Business Cycles. Review of Economic Dynamics 12 (3), 393-402.

Krusell, P., Smith, A. A., Jr., 1998. Income and Wealth Heterogeneity in the Macroeconomy. Journal of Political Economy 106 (5), 867-896.

Long, John B., J., Plosser, C. I., 1983. Real business cycles. Journal of Political Economy 91 (1), 39-69.

Long, John B., J., Plosser, C. I., 1987. Sectoral vs. aggregate shocks in the business cycle. The American Economic Review 77 (2), 333-336.

Loury, G. C., 1981. Intergenerational transfers and the distribution of earnings. Econometrica 49 (4), 843-867.

Lucas, Robert E., J., 1977. Understanding business cycles. Carnegie-Rochester Conference Series on Public Policy 5 (0), 7-29. 
Lucas, Robert E., J., 1987. Models business cycles. Basil Blackwell, New York.

Lucas, Robert E., J., 1988. On the mechanics of economic development. Journal of Monetary Economics 22 (1), 3-42.

Novales, A., Fernandez, E., Ruiz, J., 2009. Economic Growth: Theory and Numerical Solution Methods. Springer, Heidelberg Dordrecht London New York.

Pischke, J.-S., 1995. Individual income, incomplete information, and aggregate consumption. Econometrica 63 (4), 805-840.

Ramey, G., Ramey, V. A., 1995. Cross-country evidence on the link between volatility and growth. The American Economic Review 85 (5), 1138-1151.

Romer, P. M., 1986. Increasing returns and long-run growth. Journal of Political Economy 94 (5), 1002-1037.

Storesletten, K., Telmer, C. I., Yaron, A., 2001. The welfare cost of business cycles revisited: Finite lives and cyclical variation in idiosyncratic risk. European Economic Review 45 (7), 1311 - 1339.

Turnovsky, S. J., Bianconi, M., 2005. Welfare gains from stabilization in a stochastically growing economy with idiosyncratic shocks and flexible labor supply. Macroeconomic Dynamics 9, 321-357.

Varvarigos, D., 2013. Environmental dynamics and the links between growth, volatility and mortality. Bulletin of Economic Research 65 (4), 314-331. 
Table 1: Benchmark values

\begin{tabular}{|l|l|}
\hline $\begin{array}{l}\text { Preference, production } \\
\text { and policy parameters }\end{array}$ & $\begin{array}{l}\rho=0.96, \alpha=0.33, \omega=0.8 \\
\tau=0.05\end{array}$ \\
\hline Shocks & $v=0.4, \chi=0.025, \theta=0.85$ \\
\hline
\end{tabular}

Table 2: Welfare, growth and inequality effects of eliminating idiosyncratic and aggregate risks

\begin{tabular}{l|lllllll}
\hline & $\theta=1$ & $\theta=0.85$ & $\theta=0.65$ & $\theta=0.45$ & $\theta=0.25$ & $\theta=0.05$ & $\theta=0$ \\
\hline \hline$d W^{a}$ & $16.05 \%$ & $11.11 \%$ & $6.22 \%$ & $2.91 \%$ & $0.91 \%$ & $0.09 \%$ & $0.05 \%$ \\
$\sigma^{2}$ & 0.13 & 0.09 & 0.06 & 0.03 & 0.01 & 0.0003 & 0 \\
$d \gamma^{b}$ & $2.90 \% \mathrm{pt}$ & $2.10 \% \mathrm{pt}$ & $1.24 \% \mathrm{pt}$ & $0.60 \% \mathrm{pt}$ & $0.20 \% \mathrm{pt}$ & $0.031 \% \mathrm{pt}$ & $0.025 \% \mathrm{pt}$ \\
\hline
\end{tabular}

Notes:

a The percentage changes between the values of $\mathrm{W}$ when $v=\chi=0$ and $v=0.4$ and $\chi=0.025$, for different values of $\theta$.

${ }^{b}$ The percentage point changes between the values of $\gamma$ when $v=\chi=0$ and $v=0.4$ and $\chi=0.025$, for different values of $\theta$.

Table 3: Welfare, growth and inequality effects of eliminating idiosyncratic and aggregate shocks, with public policy $(\tau=0.05)$

\begin{tabular}{l|lllllll}
\hline & $\theta=1$ & $\theta=0.85$ & $\theta=0.65$ & $\theta=0.45$ & $\theta=0.25$ & $\theta=0.05$ & $\theta=0$ \\
\hline \hline$\% \Delta W$ & $12.79 \%$ & $8.93 \%$ & $5.05 \%$ & $2.38 \%$ & $0.75 \%$ & $0.074 \%$ & $0.05 \%$ \\
$\sigma^{2}$ & 0.12 & 0.08 & 0.05 & 0.02 & 0.007 & 0.0003 & 0 \\
$\% \Delta \gamma$ & $2.63 \% \mathrm{pt}$ & $1.90 \% \mathrm{pt}$ & $1.12 \% \mathrm{pt}$ & $0.55 \% \mathrm{pt}$ & $0.18 \% \mathrm{pt}$ & $0.03 \% \mathrm{pt}$ & $0.025 \% \mathrm{pt}$ \\
\hline
\end{tabular}

Table 4: Effect of changing $\tau$ from its benchmark value 0.05 to

\begin{tabular}{l|lllllll}
\hline & $\tau=0.1$ & $\tau=0.15$ & $\tau=0.2$ & $\tau=0.25$ & $\tau=0.3$ & $\tau=0.4$ & $\tau=0.7$ \\
\hline \hline$\% \Delta W$ & $0.99 \%$ & $2.08 \%$ & $3.29 \%$ & $4.61 \%$ & $6.04 \%$ & $9.26 \%$ & $22.39 \%$ \\
$\% \Delta \sigma^{2}$ & -11.55 & -22.20 & -32.00 & -40.99 & -49.22 & -63.53 & -92.34 \\
$\% \Delta \gamma$ & $-4.14 \% \mathrm{pt}$ & $-8.53 \% \mathrm{pt}$ & $-13.21 \% \mathrm{pt}$ & $-18.21 \% \mathrm{pt}$ & $-23.58 \% \mathrm{pt}$ & $-35.65 \% \mathrm{pt}$ & $-90.52 \% \mathrm{pt}$ \\
\hline
\end{tabular}

